\title{
Co-construction of Immediate context in English as a Lingua Franca Communication
}

\author{
Haosheng Xu \\ Xi'an University, Xi'an, 710065, China \\ katherine1972@126.com
}

\begin{abstract}
Keywords: English as a Lingua Franca; Intercutural communication; Immediate context; Co-construction
\end{abstract}

\begin{abstract}
Taking communication subjects, communication language and cognition schema as major variables, the author defined "context" in ELF communication as "a dynamic bi-directional immediate context with 'others' as communication subjects and 'my English' as communication language. It is co-constructed by means of activating communicators' relative cognition sub-schemas in the communicators' collaboration.
\end{abstract}

\section{Introduction}

With the deepening of globalization in politics, economy, culture, education, and other fields, English has gradually evolved from English as a Foreign Language (EFL) to English as a lingua franca, ELF (Seidlhofer, 2004). Samarin (1987) defines lingua franca as "different native speakers 'medium of communication, which is their second language". Firth (1996) defines English as a Foreign Language (ELF) as a contact language that is used between people who do not have a common native language and a common cultural background. The speaker's native language is non-English. House (1999) believes that ELF users have different native languages and cultural backgrounds, and English is not the native language of any of them. After that, the academic community mostly agreed that ELF communicators should include English as a Second Language users and English native speakers. Therefore, Seidlhofer's (2011) ELF definition is "People with different native languages use English to communicate; English is their optional language medium, and often their only choice." It can be seen that with the development of English lingua franca and the deepening of its research, our understanding of English as an ELF gradually becomes that people with different native languages use English as their linguistic media for communication, and the communication subject is different native speakers, including native English speakers, who speak English as the language of communication.

In the context of ELF, the diversification of communicative subjects has changed the communicative attributes of English language accordingly. The traditional monolingual model has turned to a multilingual and multicultural fusion and coexistence syntagmatic paradigm (Yan Yongping, Yang Qing, 2016). As ELF becomes a new normal used in English, the English communicative context has also changed, showing new features.

\section{Context in English as a Lingua Franca}

The linguistic concept of context was proposed by German linguist Wegener in 1885. Later, Malinowski (1923) first proposed the concept of "context of situation", which refers to the direct environment of language activities. In 1935 he proposed the concept of a context of culture, which was defined as the entire cultural context that regulated language activity (Malinowski, 1935: 22). Afterwards, the London school leader J.R.Firth (1968) defined the four elements of the context of situation as: participants in the scenario, including their persons and personalities; participants' behaviors, including linguistic and non-verbal behaviors; other related things and events and the effects of verbal behaviors. Hall (1976) divided the context into high context (HC) and low context (LC). In the high context, most of the information exists in the material context, or is internalized to the communicators, and is rarely stated in clear coded information. Therefore, language use plays a 
relatively minor role in communication; while in low context, a large amount of information needs to be transmitted with clear coded information, so the achievement of communicative purposes depends more on language use. Halliday, a systemic functional linguist, based on the relationship between the language form and the environment inside and outside the language, finally determined the three variables of the situation context in 1978: field, tenor, and mode. Halliday (1999) thinks that context and language are two levels. The situational context and cultural context in the context have instantiation relations. The relationship between context and language is a realization relationship between levels, in which the language embodies the situational context as a discourse and the cultural context as a systematic language. Hymes defines the four components of context: the scenario, ie the communication context; the participants, including interpersonal relationship and communicative purposes; the text, including the content, form, genre, and the transmission of information; and the pragmatic protocol, ie, social norms of communication and interpretation of communication behavior. He explained this as eight major items, summed up as "SPEAKING" (Xu Lisheng, 2006), namely: Setting and scene (background and scene), Participant, End, Act sequence, Key, Instrumentalities (information publishing tools, media), Norms (pragmatic norms), Genre (genres). It should be noted that Hymes also considers language itself as part of context.

The cognitive linguist R.W.Langacker (1987) divides the context into systemic context, situational context, and syntagmatic context. Among them, the system context involves cognitive operations such as schema network, categorization, and activation of protocol units. It categorizes the actual usage event into completely regulated or partially regulated systemic context information; the situational context are mostly external factors, such as the social status and role of the speaker/listener, the speaking time and place, the communication intention, the cultural background of speaking, etc., which can also be called "social context"; the syntagmatic context focuses on the organization, integration, or mutual accommodation of two semantic or phonological structures within an linguistic expression and it is also referred to as "language context" (Niu Baoyi: 2017). Verschueren (1999) believes that context is dynamic in the process of linguistic communication. Its fundamental feature is dynamic generativeness, and both sides of the communication are mutually contextual. "In the range of possibilities that are almost infinite, the context is created by some kind of dynamic process. It is created between the speaker and the interpreter, and in the interactive dynamic process connecting the objective external (or is considered to be objective existence) reality. So that the relevant context is bounded, even if these boundaries are unstable and there is permanent negotiation. The challenge here is to find these boundaries in the specific examples of language use rather than imposing on contexts based on a pre-conceived theoretical model." Similarly, Sperber \& Wilson (1986) also believes that contexts are dynamically generated and the result of the internalization of external information by human brains. It exists in the mind of human beings. It is the perception and hypothesis of the real world. It is a set of facts or assumptions that can be manifested, that is "cognitive environment" (cognitive environment). In the process of communication, communicators choose what they need from their cognitive environment and temporarily construct appropriate contexts of communication. Certain factors in context are needed to be activated to understand discourse.

Despite the perspectives and expression of the studies on context above are different, the comprehensive summary shows that the context study always revolves around the communicative language, communicators and the cognition of all the linguistic and non-linguistic factors related to the communicative situation. Inspired by the concept of "schema", the author borrows from the concept of "cognitive schema" to summarize the contextual element of "cognition of all linguistic and non-linguistic factors related to communicative context." Schemas include both language schemas and non-language schemas, such as social schemas, cultural schemas, and thinking schemas. Because of their relevance, relativity, dynamics, hierarchy, and contextuality (Feng Quangong, 2010), it has enough capacity and flexibility to cover all the "linguistic and non-linguistic factors related to the context of communication" in the aforementioned contextual concepts. Unlike English as the language of 'self' in EFL communication, the English communication language in the context of ELF is the language of 'others'- "other language" 
(Jenkins: 2015, cited from Yan Yongping, Yang Qing, 2016 ), which is a "my English" (ELG) constructed by ELF users to reflect self-communication and social and cultural identity (Kohn:2011, cited from Yan Yongping, Yang Qing, 2016); different from EFL communication, the English native speaker is not dominant in ELF communication. The second language speaker does not need to passively adapt or one-way closer to the pragmatic norms of native English speakers. The ELF communicators are mutually "others" and the "others" are mutual symbiosis subjects, and they are both different and co-exist. They stipulate and interact with each other in communication. In the context of ELF, the two elements of context-communicative subject and communicative language - have new properties and present new features that make the ELF context a bi-directional and co-constructive immediate context. At the same time, it also makes the ELF communication also shift from crosscultual communication to intercultural communication. The development and realization of communication needs to activate another element of the context - cognitive schema, but in the ELF communication, due to the "self nature" of the communication language and the "otherness" of the communication subject, cognitive schema activation does not happen overnight, but it requires the communicators to constantly exchange information for multiple points activation. It is precisely because of this, the communicative context in ELF also has the dynamics claimed by Verschueren and Sperber \& Wilson above.

Therefore, context in English lingua franca is a dynamic bi-directional immediate context with 'others' as communication subjects and 'my English' as communication language. It includes three variables, communicative subject and communicative language and cognitive schema.

\section{Co-construction of immediate context in English as a lingua franca communication}

It is generally believed that culture precedes communication. Communication in the EFL context is a cross-culture communication. Second English speakers need to work hard to tend to and adapt to the culture of native English speakers with efforts to overcome the negative transfer of their language and culture in English use to dispel the conflicts and obstacles in the use of language. In the ELF communication, the communicators are "others". Therefore, the direction of efforts of both sides does not tend to and adapt to the English culture, but are the introduction, coordination, compromise and mutual integration of various forms and means between the two "other" cultures. It's an interactive culture (Jin Yongping, Yang Qing, 2016) communication. It can be seen that there is no static home culture presupposed in the ELF communication, but a random dynamic immediate culture. Therefore, the context in the ELF communication is a kind of immediate context that needs to be co-constructed by both "others" communication subjects. Its means can be activating each other's cognitive schema with a language or non-language way.

Cognitive schema is the representation of knowledge, the knowledge structure that is structured in the mind of people (Carrell: 1984) and is the "pre-existent knowledge" of the world. Different scholars have made different classifications of linguistic schemas, such as linguistic schema, content schema and formal schema, or linguistic schema, textual schema and world schema, etc. The author uses contextual concepts and borrows the classification method of Zhang Siyou (2001) and divides cognitive schemas into three subschemas: cultural schema, content schema, and structural schema. In the ELF communication, the communicators collaborate to construct a immediate context by activating each other's cognitive schema.

Mutual promotion of information to each other, activating cultural schemas

Culture schema is a "structure block of knowledge" in the human brain about "culture". It is a kind of knowledge organization mode about "culture" of the human brain through previous experience that has already existed. The cultural schema helps people perceive and understand various cultural phenomena in the society, such as the knowledge structure created by the local conditions and customs, conventions, folk customs, lifestyle, social systems, ways of thinking, values, and religious beliefs. The cultural schema has a typical national character. (George Yule: 2000, cited from Lei Cai: 2007)

Due to the multicultural nature of ELF context, the common ground information between the communicators is often insufficient or asymmetric, which will weaken or mislead the pragmatic 
presupposition to some extent. So the communication subject needs to use explicitness strategies such as self-initiated repetition, simplification, signaling importance, paraphrase, analogy, questioning, etc. at any time in order to effectively activate the cognitive schema of other's cultural background at different nodes, to bridge related information gap and clear communication barriers. For example,

Extract1: (S1 is a Frenchman, S2 is a German, and S3 is an Italian, they are discussing online photo of a couple)

$01 \mathrm{~S} 1: . .$. they have picture of them

02 S2: eh?

$03 \mathrm{~S} 1$ : pictures of them you know ... in Australia in Katmandu in Tibet like

04 S2:@@@

05 S3: they sent pictures ...[ on the internet?

$06 \mathrm{~S} 1$ :[it's nice but it's a bit

$07 \mathrm{~S} 2$ : too much eh?

08 S1: cheesy

09 S2:[yeah

$10 \mathrm{~S} 3:$ [yeah

11 S2: yeah a bit too much I think

$\rightarrow 12$ S1: so ... blue flower we say ... fleur bleue

13 S3: why? ... to say that it's cheesy

$\rightarrow 14$ S1: yeah ... fleur bleue means ... you know when you have these pictures with little angels of

$15 \mathrm{~S} 2$ : ah[yeah

$16 \mathrm{~S} 3:[$ yeah

17 S1: fleur bleue

$\rightarrow 18$ S2: kitsch-[kitschig

19 S1:[kitschig yeah@@@

(the example sentences are cited from Ran Yongping, Yang Qing, 2016)

In the above example, for the blue flower (12) in the communication, S1 realized that the lack of common cultural information would cause obstacles for S2 and S3 to understand, so the active code is converted to the French word fleur bleue, which is also explicitness strategies, so S3 asked to confirm whether this French word is the same as the cheesy that agreed with everyone before (13), which is self-activation of relevant cultural schema for understanding. But seemingly fleur bleue and cheesy are not yet able to form a perfect correspondence, so S1 activated their cultural schemas with little angels (14) that was known by all of them, so that German S2 and Italian S3 immediately understand the protocol information of specific language and culture $(15,16)$ of the French word fleur. S2 then converted this information code to German kitschig (18). Three non-English-speaking communicators used the corresponding strategies to activate each other's cognitive schemas in this English communication, and co-constructed a communication context to ensure smooth communication.

Compensation and mutual assistance for clear understanding of the discourse, activating the content schema

The content schema is a knowledge memory of various contents constructed with linguistic knowledge, background knowledge, reasoning and interaction other than text as the main content (Zhang Siyou, 2001). The author fine-tunes this definition to a knowledge memory of various contents constructed with linguistic knowledge, background knowledge, reasoning and interaction other than verbal contents as the main content. This knowledge helps people deal with natural language and achieve understanding in communication.

In the ELF communication, since both or one side is non-native English speaker, their English proficiency and accuracy are not uniform. This requires both parties to use the compensation and mutual assistance strategy to activate the other one's content schema in the communication timely to help understand and output the discourse. For example, when a listener encounters a disturbance 
of discourse comprehension, the speaker can adopt a disambiguation strategy (Cogo \& Dewey 2012, cited from Yan Yongping, Yang Qing, 2016), and the speaker can also use a proactive work to deal with the potential issues of utterance comprehension of the listeners with obstacle(Mauranen 2006, cited from Yan Yongping, Yang Qing, 2016). Alternatively, code-switching, co-creating the message, and word replacement, etc., can be used to help the speaker output and complete the expression. The speaker/listener can also overt question the speaker to clarify ambiguity or semantic fuzziness in the utterance, or to clarify the listener's understanding of the utterance and meaning. As in Extract1, S1 expects that S2 and S3 do not know the French word fleur bleue, so a pre-disposal strategy is used to replace (12) the well-known English word blue flower, so that the content schema of S2 and S3 is initially activated. They can get literal meaning to construct the immediate context for the later communication.

Convergence and divergence highlight communication themes and activate structural schema

For the underlying structure of structure schema text or discourse, cognitive psychology defines it as "a unit of meaning that consists of the sequence of events and actions in a particular situation". Different articles (such as narratives, reports, descriptions, poems, explanations, letters, arguments, etc.) are different because of their connection code of topics, propositions is different with other information. This constitutes the "structure schema" of the article or speech (translated by Liu Runqing et al., 1992). The ELF communicators can use the structural schema to make pragmatic presuppositions, organize and modify the discourse structure, and monitor the discourse logic, which in turn helps to construct the immediate context needed for communication. In ELF communication, the communicators can adopt convergent utterances, divergent utterances, or conversational transition to highlight topics and activate structural schemas. E.g,

Extract 2: (Brunei student S1, S2, Malaysian student S3 and Pakistani student S4 are discussing topics related to Internet communication and face-to-face communication)

$01 \mathrm{~S} 1$ : no (.) What I meant by interaction what I meant by interactive it's that (.) like say for example I have skype and you have skype and we can TALK (.) $<1>$ we can interact (.) that one is $</ 1>$ like a (.) recorded video=

$\rightarrow 02$ S4: $<1>$ yes exactly (.) so we can share with others $</ 1>$

$03 \mathrm{~S} 1:=$ and sent over and that's it. $<2>$ you can't interact with the video $</ 2>$

$\rightarrow 04$ S3: $<2>$ it's it's just DELAYED interaction $</ 2>$ isn't it?

05 S2: actually no

06 S3: why people can comment on your video? (the example sentences are cited from RanYongping, Yang Qing, 2016)

In Extract2, S1, 4, and 2 have the same idea that online network interaction is communication, but S3 thinks that recorded video can also be communication. In their dialogue, S4 has adopted the convergence discourse with S1, activating the structural schema of them and guiding the logic to the direction of self-interest. S3 chose the discourse of diversification and expanded the logical structure. However, no matter convergence or divergences, all of them in communication are centering on the same topic and constructing the immediate context under the topic to complete the communication.

\section{Summary}

In the international context of ELF communication, the pragmatic norms of native English do not fully satisfy the communication needs, and the definitions of pragmatic norms and pragmatic competence are therefore also being updated. Context as one of the core concepts of pragmatic research also needs to be given new content in this context. This paper uses the communication subject, communication language and cognitive schema as variables to define the ELF communication context as "a dynamic bi-directional immediate context with 'others' as communication subjects and 'my English' as communication language". The key to co-construct immediate context by the communicators is believed to activate each other's cognitive schemata. The construction of immediate context is a dynamic and bi-directional co-constructed process, and 
the result of mutual support and compensation of the three cognition sub-schemas of both sides. Of course, the related concepts in this definition still need more materials and research to make corrections and improvements, and follow-up needs a lot of empirical research to confirm or falsification.

\section{References}

[1] Carrell, P. L. 1984. Schema theory and ESL reading[J]. Modern Language 68: 333.

[2] Duranti, A. \& Goodwin, C. 1992. Rethinking Context: Language as an Interactive phenomenon [C]. Cambridge: Cambridge University Press: 31

[3] Firth, A. 1996. The discursive accomplishment of normality: On“lingua franca"English and conversation analysis[J]. Journal of Pragmatics 2: 237-259.

[4] Firth, J. 1968. A synopsis of linguistic theory (1930-55)[A]. In F. Palmer (ed.). Selected Papers of J. R. Firth 1952-1959[C]. London: Longman: 177

[5] Zhang Siyou, 2001, Cognitive Schema and New English Textbooks and Teaching Models [J]. Foreign Language Teaching Abroad (3): 4-8 (In Chinese)

[6] Hall, E.T. 1976. Beyond Culture [M]. New York: Doubleday: 81-83

[7] Halliday, M. A. K. 1978. Language as Social Semiotic: The Social Interpretation of Meaning[M]. London: Arnold.

[8] Halliday, M. A. K. 1999. The notion of"context" in language education[A]. In M. Ghadessy ( ed.). Text and Context in Functional Linguistics[C]. Amsterdam: John Benjamins: 8

[9] House, J. 1999. Misunderstanding in intercultureal communication: Interactions in English as a lingua franca and the myth of mutual intelligibility [A]. In C. Gnutzmann (eds). Teaching and Learning English as a Global Language[C]. Tübingen: Stauffenburg: 73-89.

[10] Jenkins, J. 2015. Global Englishes: A Resource Book for Students[M]. Abingdon: Routledge

[11] Kohn, K.2011. ELF and the standard English Misunderstanding[A]. In A. De Houwer\& A. Wihon (eds.). English in Europe Today. Amsterdam: John Benjamins: 72-94

[12]Langacker, R. W. 1987. Foundations of Cognitive Grammar Vol.1 : Theoretical Prerequisites, Stanford [M]. California: Stanford University Press: 401-407

[13] Malinowski. B. 1923. The problem of meaning in primitive languages[A]. In C, Ogden \& L.Richards (eds.). The Meaning of Meaning: A Study of the Influence of Language upon Thought and of the Science of Symbolism[C]. London: Kegan Paul: 306

[14] Malinowski, B. 1935. Coral Gardens and Their Magic (Vol,2)[M]. London: Allen \& Unwin:22

[15] Samarin, W.1987. Lingua Franca[A].In U.Ammon, N.Dittmar, \& K.Mattheier (eds. ) . Sociolinguistics: An International Handbook of the Science of Language and Society[C].Berlin: Walter de Gruyter: 369-373.

[16] Seidlhofer, B. 2004. Research Perspectives on Teaching English as a Lingua Franca[J]. Annual Review of Applied Linguistics, (24): 209-239.

[17] Seidlhofer, B. 2011. Understanding English as a Lingua Franca[M]. Oxford: Oxford University Press: 7

[18] Sperber D. \& Wilson, D. 1986. Relevance: Communication and Cognition [M] .London: Basil Blackwell: 15-16

[19] Verschueren J. 1999. Understanding Pragmatics [M] . London: Edward Arnold: 109

[20]Feng Quangong, 2010, Discussion on the Composition of Translation Ability from the Perspective of Cognition [J]. Foreign Language Teaching (6): 110-113. (In Chinese)

[21]Lei Cai, 2007, Schema Theory and the Meaning Construction of Cultural Schema [J]. Journal of Guizhou University of Technology (Social Science Edition) (9): 153 (In Chinese )

[22]Liu Runqing et al., 1992, Longman Linguistics Dictionary, Shanxi: Shanxi Education Press: 291 (In Chinese)

[23] Niu Baoyi, 2017, "Contextual View” of Cognitive Grammar[J]. Journal of PLA University of Foreign Languages (40): 78-85 (In Chinese) 
[24] Yan Yongping, Yang Qing, 2016, English Pragmatic Competence and Its Reconstruction under the Background of English as a Lingua Franca [J]. Foreign Language Teaching and Research (48): 287-299 (In Chinese)

[25] Xu Lisheng, 2006, Contextual Theory Construction of Linguistics Research [J]. Journal of Zhejiang University (Humanities and Social Sciences)(4):158-164 (In Chinese) 